\title{
Originalartikel
}

\section{The social contagion of aspirations}

On the happiness of having a 'life style'1

\section{Birgitte Folmann}

UC Syd

birgitte.folmann@cas.au.dk

Folmann, Birgitte (2017). 'The social contagion of aspirations: On the happiness of having a life style' i Tidsskrift for Forskning i Sygdom og Samfund, nr. 26, 41-61.

Discussions of health-related behaviors and lifestyle often become theoretical and morally laden owing to their individualistic view on risk factors and life choices. This article uses the analytical concepts of contagion and configuration to explore the spread of aspirations for the good life among young men in Northern Uganda. The potential social contagion of aspirations is unfolded to provide a deeper understanding of social processes not only as dynamics between people but also as processes between people and their surroundings in a society which is subject to rapid change. This understanding will provide a sense of the meaning invested in having a 'life style' and the significance of choice. Inspired theoretically by the Weberian concept of life style, it is found that young people in Northern Uganda, although they may be limited in terms of their life chances, live their lives as well as possible by taking advantage of the little space for choice that the reality of their resources and class circumstances allows. Young people in particular seek to engage in and perform what could be described as aspirational consumption in the form of 'life styles'; and even though they rarely succeed, making some progress along this path seems important and fuels their ongoing aspiration for the good life. Having a 'life style' means being able to choose and consume, and getting a 'life style' reflects an aspiration for social mobility. Ta- 
king the emic approach helps to explain how social contagion occurs and how health-related practices are formed.

\section{"Why are you walking? Walking is only for the poor"}

Walking the noisy and dusty streets of Gulu when the light is fading and the heat gets bearable gives a good impression of how town life unfolds. You are forced to zigzag to avoid the busy people heading home, the boda bodas (motorcycle taxis, which are heavily laden, often with more than one person and goods), cars trying to navigate through the crowd, and traders offering grilled maize, fried (fast) food, vegetables and fish for sale along the roadside, making the path for traffic even smaller. I try to keep up my pace as I like to be physically active after a day of fieldwork, which generally involves sitting down all day doing interviews. It is an evening like this when Simon - one of my interlocutors, who says he lacks both opportunity and inspiration - suddenly emerges sitting on a boda boda in the growing darkness. He yells at me and says laughingly: "Why are you walking? Walking is only for the poor". Although Simon could be categorized as one of the marginalized poor young men on whom my study focuses, he provides us with a hopeful counterpoint to this category by challenging me with his bantering. I don't know how 20-year-old Simon could afford to take a boda boda that particular evening. He was unemployed and basically on his own as he had recently moved to Gulu town from his village without his family. He handled his situation by earning a little money from petty trading and poorly paid piecework, which he took on a day-to-day basis. And even though he lived in a cheap, basic room, sharing with six other young men for a low rent on the outskirts of Gulu, I know that paying the rent and even getting food on a daily basis was often a challenge for him. Life in Northern Uganda is known to be tough: the region is recovering from a civil war that lasted more than 20 years, and in the aftermath of the war young urban poor people have few chances to get an education or a job in town. For a young man like Simon, navigating the impasse of being young and poor, the good life is comprised of more than getting about in daily life. The good life is not only a state to be obtained, but an ongoing aspiration for something better that gives meaning to life's pursuits. 


\section{Introduction}

In this article, I address the question of aspirations for the good life and the epidemic potential of this kind of aspiration among young people in Uganda. Shared ideas of the good life emerge in processes of social influence, for instance when the behaviour of one person inspires or is copied by other people. In this article I will refer to this as 'social contagion' (see Grøn and Meinert, forthcoming 2016). The inspiration from others is a kind of communication or transfer of something between individuals, so the term 'social contagion' is similar to the kind of contagion known from the spread of bacteria and viruses. The young men in the study are inspired by others who have a cool way of living - or as they frame it: 'who have a life style' - and this inspiration prepares the ground for aspirations that seem to be contagious. By moving to town and being in the physical proximity of others who have a desired lifestyle, such inspiration leads to aspirations for another life. My empirical basis will be young men, for whom aspirations seem to have the power to move and motivate for another life expressed in the desire for 'having a life style'. These aspirations are social processes with a relational character which are sited in time and place. In Northern Uganda, they are configured in terms of the post-war context, demography, cultural values and collective experiences. By exploring what spreads and how it spreads in this particular empirical setting, and by analysing it as a dynamic epidemic phenomenon, this article contributes to the understanding of cultural epidemics in order to learn more about what happens in these inherently intersubjective processes. Although the scope of this article is to explore social contagion, it ultimately contributes to insights in young urban men's way of living, which is potentially harmful to their health, and to a more profound understanding of how health-related behaviours are formed ${ }^{2}$.

As the point of departure for the analysis of 'contagious aspirations' I will employ another type of reasoning that historically accounted for epidemic disease: the notion of configuration (Rosenberg 1992). By using configuration and contagion as analytical concepts, I follow the lead of Seeberg and Meinert (2015), drawing on Rosenberg's definition of these concepts (1992: 295). In order to understand the social process of contagion, it is necessary to look the specific context in which a social epidemic takes its starting point and develops. Following a line of argument taken from biomedical history, using the notion of configuration implies a focus on environment and social life (Rosenberg 1992). In social epidemics, precisely as in infectious epidemics, the contagion processes are fuelled by the unique configuration of circumstances that comprise the specific social and 
cultural world, emphasizing the role of structures and the interconnectivity between people and their surroundings. Identifying the specific contagion (what is spreading) and the configuration (the basis for the epidemic potential) is central, but the article also focuses on the dynamic relationship between configuration and contagion. A focal point in the configuration is the concept of lifestyle, which will be analysed and discussed in the article as both the emic concept of life style, and the theoretical concept of life style inspired by Weber. My interlocutors are inspired by others, and these inspirations form the basis of aspirations expressed in the notion of 'having a life style'. Aspirations are hopes for the future informed by shared ideas of the good life, and I see aspirations among urban poor in Gulu and the social processes influenced by their surroundings as social contagion.

After a description of the fieldwork, a section about configuration will follow. These paragraphs provide the basis for the analysis of aspirations as social contagion.

\section{The fieldwork}

Gulu, the site for my fieldwork, is the biggest town in Northern Uganda, and it is growing rapidly: from around 40,000 people in the early 1990s to approximately 154,000 people in 2011 (Ugandan Bureau of Statistics, 2012). With this rapid urban growth, the outskirts of Gulu are characterized by unplanned settlement areas inhabited by a mix of both families and individuals - generally low-income households. Young people out-of-school are overrepresented among the urban poor. Most urban young people live in these unplanned settlement areas, often in squalid conditions, sharing very little space in rented rooms or huts, and are exposed to high levels of unemployment. The majority of the population in Northern Uganda are Acholi in terms of their ethnic origin, but with its rapid urbanization and proximity to Southern Sudan, people with other ethnic origins are also numerous in the Gulu area.

The empirical material that provides the basis for the analysis was collected during six weeks of anthropological fieldwork between early 2013 and 2014. The work is also based on more than one year in the field during the years of my PhD research from 2008 to 2012. Interlocutors were recruited partly from families that I knew through the PhD fieldwork, and partly from people that I got to know via the Gulu Youth Center and during evenings at places like sports betting clubs and 'pork joints' where young people hang out. The data comes from semi-structured 
interviews and more informal conversations with the young men. Field research also involved many hours of observation and participation in local activities, extensive informal contact with residents, and numerous unstructured conversations with key informants. I also participated when some of my interlocutors went looking for piecework on a daily basis.

\section{The configuration perspective}

The configuration perspective, and its structural and relational aspects, emphasize the multiple relationships between social contagion and the natural and social environment. In uncovering the configuration in a specific context, a large number of elements have to be considered in order to understand the basis for social contagion. However, I will focus on a few vital elements that seem to have great importance for the spread of aspirations among young men in Gulu: the post-war context, urbanization, consumption and the concept of life style.

\section{In the aftermath of war}

Between 1986 and 2006 Northern Uganda was affected by one of the most drawnout armed conflicts in Africa. From 1996, the government of Uganda started forcibly displacing the people of Northern Uganda and putting them in so-called "protected villages", also commonly known as IDP camps. Over the next ten years, up to 1.8 million people (IDMC, 2010) - the great majority of the Acholi population - were forced by the national military, UPDF, to leave their local villages and live in camps which were established around local trading centers, supposedly to protect the people from attacks in the villages by the rebel army LRA. The living conditions in the camps, however, were extremely poor, leading prominent social scientists to accuse the Ugandan government of "social torture" (Dolan, 2009) and of "displacing human rights" (Branch, 2011). Thousands of people lost their lives through violence, starvation or war-related diseases and epidemics (Vorhölter 2014). During the conflict, urban life differed considerably from life in the camps. Children and young people in town had better access to education and other services (e.g. health and counselling, leisure activities, media), which were provided or supported by international development organizations, particularly during the last years of the war. Although the focus of NGOs, particularly the 
distribution of food aid, concentrated on the people in the camps, urban children and young people were an important target group of aid agencies and were thus greatly exposed to Western development discourses and practices (cf. Verma 2012). It is against the backdrop of the instability of war and displacement that the social contagion of aspirations is constituted. Despite improvements and pervasive socio-cultural changes during my fieldwork, the majority of the population still suffered from poverty, high unemployment rates and the lack of quality education (Branch, 2008; Whyte et al., 2012; Spitzer \& Twikirize 2013). Gulu town is the site of profound urban growth, and young people account for a large percentage of this growth. It is estimated that as many as $60 \%$ of all urban dwellers in Uganda will be under the age of 18 by 2030 (Ugandan Bureau of Statistics 2012). Despite young poor people reach town, it is likely that both insecurity and stimulation mark their lives to a significant degree. But the swirl of the 'new' and the 'modern' have a magnetic attraction, and young men who do not want to be viewed as "backward" or "bushy" are eager to master this lifestyle. Despite the lack of opportunity for formal employment, urban young people are attracted to a more global, "Western" (youth) culture. Inspired by the media, which convey images of a glossy modern future, young people in Gulu dream of a prosperous life in urban Uganda, and do not want to return to a life of rural farming as practiced by previous generations before the war (Vorhölter 2014). Many of my interlocutors in Gulu expressed a desire and a need for change. They felt dissatisfied with their current situation; and even though many of them expressed hope for the future, they also said that their daily realities contrasted a good deal with images of a modern lifestyle presented in the media - of wealth, prosperity, consumer culture, and individual freedom.

\section{Consumption: drinks and food}

It is important to analyse the fact that consumption as part of everyday life is becoming more and more relevant (even in countries where many households can barely afford to consume anything) in order to understand this configuration as a basis for social contagion. In the following I will only briefly touch on the subject of consumption, because it is not my intention to explain consumption as such. Instead, I wish to use observations about consumption to describe one element of the configuration that is important in order to understand the social contagion of aspirations. The case presented here reflect the above-mentioned economic difficulties and explain how the young men are persuaded by the hope for prosperity 
and a western lifestyle that is revealed to them via the media, advertisements, on television and on the radio. In the conversations and interviews I conducted, young people were fascinated by the lifestyle they often described as 'westernized' and which they linked to material wealth (especially phones, nice clothes, and food). In the urban public sphere of Gulu, the discourse of consumption and commodification was ever present, mirroring the middle-class aspirations among the population. The big billboards which are located in many places in Gulu town display people who are happy and modern, placed in surroundings which bear very little resemblance to the living arrangements of most people in Gulu. Beverage companies are often present in the advertisements, spreading the message about refreshment, happiness and a modern lifestyle. At the time of my fieldwork, Coca-Cola was a strong brand distributing messages of optimism and happiness (by picturing a cool lifestyle) in their campaign 'Open happiness' and the later 'Shared happiness', which had resonance for my interlocutor. As Morris said, "not often - but sometimes I buy a soda. I can go all day and dream about it.... when it is hot and dusty, I am just longing for that moment... [laughing] iya yom loyo [a fixed concept, meaning 'makes me even more happy']'. The 'sharing happiness' campaign gained a widespread foothold because it was sensitive to local culture with a perfect fit between idea and medium. The product is also valued because it alters your physical state (bringing happiness). 'Sharing' is important in more than one sense, because by sharing you are living up to social ideals, and by 'sharing happiness' you also 'share' your identity. The value assigned to the product depends not only on its assessed (promised) transformative power in the physical world, but also on its capability to position its owner within the space of a differentiated social world (Beckert 2010).

Soft drinks were not the only consumer commodity that was highly valued by many people in Gulu: fried food (commonly referred to as 'soft food') was also very popular. According to 19-year-old George:

"From what I understand about it [soft food], it's basically a kind of food which is soft and easy to digest. It is food that is fried and has a great taste. When you are hungry it satisfies you much more than the traditional food, which is hard to chew. Soft food makes you stronger..hm..gives you gupu [strength/power]".

It is a widespread stance that fried food is better than boiled food. The food people buy along the roadside is usually fried in plenty of oil, and vendors often ask you if you would like to have extra oil added. The production and consumption of 
cooking oil is perhaps increasing more than any other food product in Uganda (Whyte 2014). For many people, being able to fry food is an extravagance they cannot afford; but the use of cooking oil has positive connotations. Various types of cooking oil are produced in Uganda, and many different brands are sold locally. The thing that diverse cooking oils have in common is that they are marketed as a natural, cholesterol-free, nourishing product which will ensure that your family enjoys good health. Supermarkets in Gulu (which are mainly for the middleclass) have allocated large parts of their shelves to different brands of cooking oil, alongside messages about their health benefits. Fred - one young bank clerk who once showed me around in the biggest supermarket in Gulu - revealed that even though he could afford to buy cooking oil in larger canisters in the supermarket, he preferred to buy it from small kiosks in tiny amounts whenever he was cooking. In town and even in the most remote areas in the districts, there was a flourishing market for cooking oil sold in small plastic bags or in bottles that people bring with them from home. Food commodities like cooking oil have value because consuming cooking oil makes a difference to the consumer: it makes food taste better, but it is also valued owing to its potential performance. The discourse about the happiness of consuming and the healthiness of the intake of for example cooking oil was obviously present in the urban landscape. The market, the goods themselves, and the massive presence of modern lifestyle discourses in the media, on large billboards and in daily conversations constitute an important part of the configuration.

\section{Lifestyle: The theoretical concept}

In the scholarly literature on public health, the concept of lifestyle in the Global North has a direct association with health-related behaviours and lifestyle practices involving considerations of health outcomes. Whereas people may have more or less taken their health for granted in previous historical eras, this is presently not the case. Health in late modernity in the Global North is viewed as an achievement - something people are supposed to work at if they wish to enhance their quality of life and avoid the risk of chronic illness and premature death (Clarke et al. 2003). In this light, lifestyle issues are aspects of health-related behaviours and conditions which entail an element of personal action at the individual level (Cockerham 2005). In the twentieth century, chronic diseases replaced acute diseases as the major source of human mortality and morbidity in most areas of the 
world, and this epidemiological transition underlined the importance of the efforts made by individuals. Medicine cannot cure these chronic diseases, and negative health lifestyles promote them. The realization that this is a certainty carries with it the revelation that the responsibility for personal health ultimately devolves on each individual, and that good health depends on healthy living (Crawford 1984). In medical anthropology the term lifestyle has been disputed by critics who put emphasis on seeing life conditions as the fundamental problem when it comes to health-related behaviour (see Lupton 1995; Scheper-Hughes 1992; Baer 1992, Pfeiffer and Nichter 2008; Farmer 1999; Benyshek, Martin and Johnston 2001). Life conditions are seen as involuntary living conditions determined by structures mirroring inequality in economic, political and social factors that influence the health of people. This discussion of lifestyle (a way of life the individual can freely choose to have) and life conditions (which are structures you cannot influence) is pertinent, and as Whyte puts it: "social and economic inequalities constrain the choices of many people, particular in Africa" (Whyte 2014:189). Many poor people feel that they do not have much choice in what they eat and how they live. Recently, particularly in urban areas in Uganda, the biomedical discourse of lifestyle and especially 'lifestyle health products' has become more evident. This new development features a discourse about how to live in order to avoid the risk of modern life and new chronic diseases such as diabetes, hypertension and obesity. National Englishlanguage newspapers in Uganda have articles and sections about health and lifestyle, and national and local radio broadcast several programs each week on health and on how you should live (eating, hygiene, seeking medical care etc.). Even though health promotion talk and health commodities are spreading in the urban landscape, they are not on the agenda for the vast majority of people (Whyte 2014). As the epidemiological transition from acute (communicable) diseases to chronic (non-communicable) diseases is still incipient in Uganda, the awareness of the link between negative lifestyles in the biomedical sense and chronic disease is not particularly widespread among the population. Lifestyle is basically something that you have when you live in the urban area and are able to flash certain signs of modernity like consumer goods. When I asked young men in Gulu about who has a lifestyle, 22-year-old Morris answered as follows, an answer which was representative of many other young men like him: "Those traditional people in the village, they don't have a 'life style'.... 'life style' is something you can get when living in town". The lack of awareness of the link between how you live and eat and your risk of becoming ill does not mean that people in Gulu are not concerned about being healthy, but they clearly attach importance to issues that do not match the 
discourses of public health authorities. In the following I seek to substantiate what constitutes the concept of lifestyle seen empirically and analytically. My starting point is not what constitutes good health-related behaviour as conceptualized in the biomedical discourse of lifestyle; or how social, political and economic structures influence health as in the medical anthropological discussion of life conditions. Instead, I focus on an analysis of the concept of 'life style' as it is conceived by my interlocutors. On the basis of emic reflections on the concept of 'life style', and for the purpose of analysis, I will introduce a theoretical framework based on the sociological theory of agency and structure, with a focus on life choices and life chances drawing on a definition of lifestyle as: collective patterns of practices based on choices available to people according to their life chances. This definition incorporates the dialectical relationship between life choices and life chances proposed by Weber in his lifestyle concept ([1922:531-39] 1978:926-39). The element of choice, the attempt to obtain a certain lifestyle, and how being able to choose are influencing your life chances seem to be analytically important.

Much of what we know about lifestyles has its theoretical origins in the early twentieth century work of Max Weber ([1922] 1978). In a Weberian context, life choices are a proxy for agency and life chances are a form of structure. Whereas health and other lifestyle choices are voluntary, life chances, which primarily represent class position, either empower or constrain choices. Weber associated lifestyles not with individuals but with status groups, thereby showing that they are principally a collective social phenomenon (Weber 1978). Status groups are groups of people with similar status and class backgrounds, and they arise because they share similar lifestyles. People who wish to be part of a particular status group are required to adopt the appropriate lifestyle. Class circumstances, age, gender, ethnicity and living conditions determine your life chances. Weber was apparently ambiguous about what he meant, but the term is usually associated with the advantages and disadvantages of relative class circumstances. Weber's thesis is that chance is socially determined, so social structure is an arrangement of chances (Cockerham 2005, see also Cockerham, Rütten and Abel 1997). The term 'life choice' refers to the self-direction of one's practices. It is an English language translation of Lebensführung, which in German literally means conducting or managing one's life. Weber (1949) argued that individuals have a capacity to interpret their situation, make deliberate choices and attach subjective meaning to their actions. Life chances (structure) either constrain or enable choices (agency), but it is important to remark that even when life chances are few, choice (agency) is not passive as the individual often has a choice (or agency) to consider their 
course of action. People therefore align their objectives, needs and desire with the probability of achieving them. Unrealistic choices are not likely to succeed or to be preferred, while realistic choices are based upon what is actually possible (Cockerham 2005; Archer 2003). However, even though life chances and life choices are separate components in the activation and conduct of a lifestyle, they are also interactional and this is also mirrored in my interlocutors' reflections on their situation. For example, when Charles is talking about his eating habits he tells me that he regularly eats food at 'hotels'3: "If I had the chance I would leave the beans completely... but meat is so expensive". He also prefers to drink sodas every day: "Sodas are good for your health. They strengthen your bloodstream and are refreshing. They actually increase your blood. If I have only a little money, I like to buy a soda instead of food. I feel strong when I drink it - and people they will know.....know that there goes a guy with style". On many occasions in the field I have been puzzled when talking with people like Charles who, like many of my other interlocutors, has limited financial resources and for whom it is a struggle to get food on a daily basis. Granted his challenged financial circumstances, it seems irrational of him to buy sodas. I also often encountered people who preferred to buy sweet biscuits for their kids to take to school rather than offering them a second or third meal during the day, or people who could talk excitedly about periods of time when they were able to have breakfast with 'escort' - that is tea (with sugar) accompanied by fried bread like mandasis or samosas. If we analyse this in the perspective of life choice and life chances, it becomes clear that despite their limited life chances, people deliberately adopt a life style which utilizes the little space for choice that their resources and class circumstances allow. The ability to choose sodas, lots of meat, sweet biscuits and fried food even for breakfast is what my interlocutors call the ability to consume 'rich food', and this rich food has not much to do with the mere satisfaction of physiological needs. It is food that is meant to be 'shared' figuratively with those we wish to impress, showing that you 'have a life style'. Some would call it conspicuous consumption, a term coined by the Norwegian sociologist Veblen (1899), referring to consumers who buy expensive items to display their wealth and income rather than covering their real needs. However, this approach places too much emphasis on the effects of structure on individuals, without taking into account the creativity of social agents. If the reality of everyday life is to be captured, it is imperative not to dismiss the actions and conduct of life style (choice and chances) as being the effect of structure on personal choice alone. The desire for senseless food commodities, the sensuous feeling of being refreshed, and the seemingly profound social urge for recognition by consuming are all factors that 
show the dialectical connection between choices and chances. Although it was rarely possible for my interlocutors to eat 'rich food' or spend money on taking a boda boda like Simon, they commended the few chances they had. Despite the irrationality of buying 'rich food' instead of staple food, it was still a realistic choice based upon what was actually possible. Choice is essential for happiness in societies dominated by consumerism.

\section{Lifestyle - the emic concept: Life style is inspirational}

At the popular place to eat pork, referred to locally as the 'pork joints' on the outskirts of Gulu town, the happiness of choice was articulated by many of my interlocutors. Pork joints are not only popular eating places, but also important urban spaces for social gatherings. At pork joints young urban Acholi people come together from different segments of society, men and women, local elites, students, underpaid workers and school leavers. In a focus group discussion about choice that I had with young students, the subject of choosing to do nice and enjoyable things like eating out at the pork joint was discussed. A few of my respondents agreed that going to the pork joint was superfluous, but most of the young students in the group explained how wonderful it was for them to be able to afford such an extravagance on rare occasions, and that it was important to save money so you could do things of your own choosing every now and then. There was a general consensus that even though going out for food and beer was expensive, it was also particularly valuable for them. Hanging out at pork joints seemed to be associated with ideas of the good life and a degree of agency. It is also consistent with common narratives of conducting an anticipated lifestyle. As Odong Patrick explained to me:

“....the 'pork joint' is a 'place for big people', you know people with money..... if I could afford it, I would come here every evening. You can come here without buying anything, but sometimes it is painful that you don't have money. You see, when you return to town, you leave the village stuff in the village, and you have to cope with life style in town. Having a life style, man, that's all about having a life style".

The above analysis of choice shows that agency is an individualistic, but also a social phenomenon. Choices depend upon social relations for their realization (Ratner 2000). As merely an individual wish or action, agency or the context of choices, 
has social intentionality in that it is sensitive to and integrates itself in social relations. But interpreted differently, individual actions can affect choices, as well as the sources of intentionality that can inspire and constrain. Specifically inspiration seems to be linked to life choices and the conduct of a lifestyle. The inspirational aspects of choice are often framed positively, as one young man accentuated when talking about his roommate, who had won a tidy sum of money on sports betting:

"...nothing is impossible. Take my roomie. He works in that sport betting place. You know - as a cleaning boy. But he gets insights... and one day he was given a huge tip from some customer.... and he gambled and luckily he won this money. So he was lucky, but he used his insights and had the courage.....this is inspiring - he is an inspiration for us all".

Many other young men are also willing to try their luck and are inspired by stories of young people acquiring quick money on betting. They do not have much choice and are often constrained by unemployment and a lack of opportunities for young urban migrants. They would rather try their luck and hope to win so they can meet their pressing needs, trying to make a living rather than living without any hope at all. Many of the young men I met during fieldwork were preoccupied with sports betting because of its promising aspects, but also because it is easily accessible in the urban environment. But inspiration has to come from the immediate vicinity, as a certain form for proximity is needed for the activity to be inspirational. This fact is underlined by Ocen:

"Well, living here is not so much different from the East, from the West, but with Kampala - life is a little bit different, because down there you can get inspired (...) there are so many influential people who you see around. It is not like here, there is no-one who inspires us so much. (...) So you get inspired when you are kind of close with the people who inspire you. The inspiration is still low".

In this comment Ocen frames inspiration negatively - or at least the probability of inspiration in the local context. He emphasizes that life in the capital city is a source of inspiration; but even though he comments on this inspiration from the capital city, he had also been inspired by urban life in Gulu after moving from life in a village to the urban periphery of Gulu. Inspiration, as we can see here, is associated with some form of influence which motivates you to do something. To be inspired, the most important thing is the source of inspiration, but proximity 
is also vital. It seems as if inspirational influence is a transfer of something very tangible and in the Northern Ugandan urban context it fuels hope and ambition and affects life choices among the young men. When you are affected by social influence, the behaviour of others inspires you and it is these lifestyle inspirations that nourish hope and resonate with the development of aspirations.

\section{Aspirations}

Many of the young men in my study chose to try their luck in town instead of banking on life in the village with traditional jobs such as farming. Whereas inspiration is related to the influence that makes you do something, aspirations are driven by hope. The Oxford Dictionary defines an aspiration as "a hope or ambition of achieving something" (Oxford Dictionary 2010). Aspirations form hope, and this hope is seen as a future or a dream of a future that will fulfil their desires. Hopes can define the type of person you want to be, the life that you want for yourself or anything that you feel would be good to be associated within your identity. The way you conduct the part of your lifestyle over which you have control depends on your life chances, and it forms the stage on which aspirations may develop. In the following I will turn to the aspirational quality that drives agency, but which may be limited by available opportunities. Aspirations form hope for the future, despite the limitations imposed by your life chances. If you identify yourself with other class circumstances and believe you can change your circumstances, this will affect your life choices in many different ways - which will in turn affect your life chances. Ultimately it is this forward-looking, aspirational capacity that drives life choices, and it is these shared aspirations; the hope for a better life (symbolised in getting a life style), I will argue, that are socially contagious.

\section{The social contagion of aspirations}

In the above part of the article we have seen, how important aspirational capacity, expressed by inspiration and being able to choose, are to my interlocutors in Gulu. When asked about their wellbeing and what constitutes a good life, people in Northern Uganda often say that adequate material resources, physical health and safety, family and social relations are essential ingredients. These elements are important but insufficient in themselves. In what follows, I add the elements 
of aspiration and opportunity, as expressed by the young men in the study. Wellbeing requires a capacity for aspiration (being able to choose) as well as the agency and opportunity to make the realization of these aspirations seem possible. Appadurai underlines that aspirations have to do with wants, preferences, choices and calculations. He reminds us that "aspirations are never simply individual (as the language of wants and choices inclines us to think). They are always formed in interaction and in the thick of social life" (Appadurai 2004:67). In developing his argument further, Appadurai (2013:187-89) also distinguishes specific aspirations (which "form parts of wider ethical and metaphysical ideas that derive from larger cultural norms") from the capacity to aspire, conceived as a navigational capability ("nurtured by the possibility of real-world conjectures and refutations"), mapping the steps from here to there as oriented by cultural visions of the future. This perspective recognizes the strategic element of choice, the substantive basis for control over one's destiny, and the subjective sense of desire (Fisher 2014; Fisher and Benson 2006; Moore 2011). Notions of the good life give direction to aspirations for agency, as well as providing a dynamic framework with which to interpret one's own actions and those of others; but they are bound by the realm of what is possible, as discussed above. When interviewing young men in Gulu, it became evident that moving to town and envisioning urban life was ultimately linked to desires and aspirations for the good life. The young men saw it as a meaningful project and a way to achieve a better life as they conceive it. Moving to town and trying to make a living there provides a path for upward social mobility for the young men: it stokes aspirations and channels agency. Even though the transition to a life in town results in opportunities that village life could not provide, the young men say that their life is difficult, that they have to work hard, and that they feel vulnerable due to the lack of job and educational opportunities. But many of them also expressed the joy of being on their own and specifically being (possibly) financially independent from their family. Gulu is geographically pivotal for the new market of Southern Sudan, so the job market in Gulu had rapidly changed due to a demand for workers to load trucks, build storehouses and retail goods, which increased the aspirational possibilities for many young school leavers trying their luck in town. The expanding market in Southern Sudan has created new opportunities for young men, turning Gulu into a venue to exercise their agency and pursue their aspirations. Moving to town is not an end in itself, but the means to achieve another end: a better life - or at least it has aspirational potential. Life in town (and the lifestyle which you can acquire a taste for there) is representing the 
good life. Although the navigational capability is restrained by the circumstances you find yourself in, the capacity to aspire seems vital.

\section{Odong's story}

The story of Odong moving to Gulu is one example out of many. At 18, with an absentee father and ten siblings, Odong dropped out of school before the final year and took up farming. In the absence of his father, his paternal uncle, the head of the family, who was living in Gulu, was very unhappy with his decision to leave school, but he gave him a small plot of land to cultivate to finance his return to secondary school or vocational school at a later date. Odong followed his mother, who moved to their village after the war. At first he did not know much about farming and did not make much money out of it. His idea was to try to earn enough to save money to complete his A-levels. But farming was hard work and yielded only a little profit. So he turned to charcoal production, which he thought would earn him money faster. "aij - it wasn't easy. Making money, you know. Mot mot matec [meaning 'very slowly']. If I was lucky I could get one or two sacks of millet. And since the bush was near and trees grow wild on our land, I turned to making charcoal". But Odong soon got tired of the hard, dirty work with charcoal and gave up life in the village. He moved back to Gulu town:

"I tried, but I don't belong in a village, because - what I want in life is not there. The village is only for the farmers. Well, for me I don't look like somebody who can dig, for me to survive I use my head, I don't use my energy...It was a mistake to go there in the first place. Moving to town hasn't allowed me to have the life I want, but it moves me in that direction, and that is something"

Young men like Odong construct their aspirations in the difficult circumstances in which they find themselves. Moving to town is seen as an opportunity in which they can act and work toward ends that they value, even if those ends are conditional and limited. The young men I interviewed see this 'new life' as a benefit, but they also see it as means to larger ends, "the life one values", which involves being able to establish a family, buy land and achieve a degree of financial security. They saw life in town as a useful means to realize their aspirations for a better life, even though the life style they aspired to was far from being achievable. 


\section{Aspirations for the good life}

Aspirations about the good life exist in all societies, as Appadurai (2004) reminds us, but the construction of the good life varies according to your life chances. But in every case, aspirations for the good life are part of a system of ideas which locates them in a larger map of local ideas and beliefs about life. To express a horizon in choices made and choices voiced, often in terms of specific goods and outcomes, often material and proximate, are "bundles of individual and particular wants, which are tied up between more general norms, presumptions and axioms about the good life, and life more generally" (Appadurai 2004:67). So even though individual enactments of aspirations are common, collective horizons of what constitutes the good life seem to involve shared values, attitudes and orientations, which (in certain conditions) become the basis for the spread of a common social identity for the participants. Aspirations in this sense are hopes for the future informed by shared ideas of the good life. These ideas are socially contagious given that aspirations give direction to agency - a power to act and the sense of having control over one's own destiny, and being able to choose what to do. Michael Jackson (2011:184) believes that "a sense of hope, a sense of a way out, is crucial to the ability to endure. Equally crucial is a sense that one is able to act on the situation that is acting on you - that one can give as much as one can get". So even though aspirations give direction to agency which suggest that the individual is generating and consciously 'having' beliefs, emotions and certain behaviours, Jackson underlines the vital nature of the possibility of being able to act on elements of the configuration. In some very real sense, individuals act on beliefs, emotions and behaviours, but these practices are nurtured by the configuration and the social context. To be able to have a life style' is a token of the good life and something you can aspire for. These particular aspirations seem to be catching among the young men in this particular setting in Northern Uganda.

The stories of the young men show us that although they have to strive for daily survival, they are also preoccupied with other objectives involving being able to afford another life and thereby lifestyle. The 'cool' lifestyle that they desire involves living independently in an urban environment and occasionally going out with their friends for beer and fried food. Since striving for a good life involves efforts to live a life you deem worth living and becoming the sort of person you want to be, this struggle cannot be seen purely as an individualistic project. It is also a product of ongoing processes of socially situated negotiation, aspirations 
and longing that seem to be contagious and that are continually enacted through the dialectic of everyday social life.

Analysing the emic concept of lifestyle as part of a social process of contagion shows that it is influenced by both agency and structure. The analysis contextualized lifestyle, recognized lifestyle choices and life chances as a collective social phenomenon in order to add detail to the discussion of lifestyle by contrast with life conditions. The way in which the individual conceives and performs life style, the aspirational drive to choose and seek chances, is essential in understanding how aspirations for the good life can be understood as socially contagious.

\section{Conclusion}

In this article, I have applied the framework of configuration and contagion in an attempt to analyse the spread of aspirations for the good life and having a life style in Uganda. A configuration is characterized by several variables which are vital if a social epidemic is to occur. The contagion perspective alone has a unilateral focus on what is actually spreading from one person to the other - in contrast to seeing the dynamics between configuration and contagion, which are more interactive and contextual and emphasize multiple social processes and the relationship between the individual and the collective. Local and situated ideas and experiences of what constitutes the good life and what it means to 'have a life style' inform us ethnographically about the social process of contagion. I have referred to the configuration as the basis for the social process of contagion. This analysis enables us to see, at one moment in time, how the specific configuration of value, attitudes and historical context influences the spread of aspirations. Aspirations are socially contagious because they stem from inspirations in the physical proximity and these inspirations are fertilising the ground for aspirations that are at once individual and collective. Seeing aspirations as socially contagious explicate how aspirations are bound to much more than individual choice and that they are social processes formed by the configuration. The notions of desire, hope and the joy of having a choice mount from the specific configuration which is historical specific and permeated by social dynamics in the post war context. Rather than explicating social epidemics in terms of the essence of the contagion, we must look at dialectical nature of choices and social structures in the specific configuration. The individuals' conscious choices work upon prior motivations, which are (sha- 
red) ideas and ideologies of the individual but they, as they are bound to sociality, also works on choices.

By moving from their rural homes to provisional dwellings in town, the young men in this study play a part in the urbanization in Uganda, adopting a way of life that involves a nutritional transition and a life with less physical activity. But health and the risk of getting ill are not their main concern. The young men wish to live an urban life inspired by a 'modern' life style, which is defined based on the ever-present discourses on consumption, middle-class life and prosperity in the urban space.

\section{Notes}

${ }^{1}$ In this article, I will write the emic concepts in italic. The emic concept of life style is difficult to reproduce in writing as it is pronounced locally, because my interlocutors use the English word for lifestyle. In the local language, Acholi, the word for lifestyle is kwo maraca, but this term usually has a negative connotation describing young people who have a bad lifestyle. The emic concept of 'having a life style' is often used synonymously with the concept of 'being westernized'.

${ }^{2}$ Non-communicable diseases, such as diabetes, are rapidly spreading in developing countries fuelled by rapid urbanization, nutrition transition, and increasingly sedentary lifestyles. Uganda is reported to have 560,000 registered diabetes patients, and figures are expected to double by 2025 (Shaw J.E., Sicree R.A., and Zimmet P.Z., 2010). Social determinants play a significant role in the spread of disease. Diabetes is labelled as a non-communicable disease, which means that it is a disease that is not infectious or transmissible. However, social processes play a role in the spread of the disease, and there is a clear correlation between living habits and health.

${ }^{3}$ In Acholiland 'hotels' are very small restaurants with 2-4 tables - not necessarily places where you can stay overnight.

\section{References}

Appadurai, A. (2004). "The Capacity to Aspire: Culture and the Terms of recognition”. In: Culture and Public Actions, Rao V. and Walton M., (eds), pp 59-84. Stanford, California: Stanford University Press

Appadurai, A. (2013). The future as a cultural fact: Essays on Global condition. London: Verso 
Archer, M.S. (2003). Structure, Agency and the Internal Conversation. Cambridge. United Kingdom: Cambridge University Press. https://doi.org/10.1017/cbo9781139087315

Baer, H. (1982) On the Political Economy of Health. Medical Anthropology Newsletter 14(1): 1-17. DOI: 10.1525/maq.1982.14.1.02a00010

Benyshek D.C., Martin J.F., Johnston C.S. (2001) A reconsideration of the origins of the type 2 diabetes epidemic among Native Americans and the implications for intervention policy. Medical Anthropology. 20(1):25-64. DOI:10.1080/01459740.2001.9966186

Branch, A. 2008. Gulu Town in War... and Peace? Displacement, Humanitarianism, and Post-War Crisis. London: LSE (Crisis States Working Papers Series No.2).

Clarke, A.E., Shim, J.K., Mamo, L., Fosket, J.R., \& Fishman, J.R. (2003). Biomedicalization: Technoscientific Transformations of Health, Illness, and the U.S. Biomedicine. American Sociological Review 68: 161-94. DOI: 10.3280/SES2009-EN2014

Cockerham, W. (2005). Health Lifestyle Theory and the convergence of Agency and Structure. Journal of Health and Social Behaviour 2005, Vol 46 (March): 51-67. DOI: $10.1177 / 002214650504600105$

Cockerham, W., Rütten, A., and Abel, T. (1997). “Conceptualizing Contemporary Health Lifestyles: Moving beyond Weber." The Sociological Quarterly 38: 321-42. DOI: 10.1111/ j.1533-8525.1997.tb00480.x

Crawford, R. (1984). A Cultural Account of Health: Control, Release, and the Social Body. In Issues in the Political Economy of Health Care, edited by John McKinley. New York: Tavistock

Dolan, C. (2009). Social Torture - The Case of Northern Uganda, 1986-2006. New York: Berghahn

Ezzati M, Vander Hoorn S, and Lawes CMM (2005). Urbanisation and health. Clin. Med. 2005;5:137-141. DOI: 10.1371/journal.pmed.0020133

Farmer, P. (1999). Infections and Inequalities: The Modern Plagues, updated edition. Berkeley: University of California Press.

Fisher, E. F. (2014). The good life. Aspiration, Dignity, And the Anthropology of wellbeing. Stanford University Press

Fisher, E. and Benson, P. (2006). Brocoli and desire: Global connections and Maya Struggles in Postwar Guatemala. Stanford, California. Stanford University Press

Grøn, L. og Meinert, L. (in press). Introduction. Special Issue on Social contagion and cultural epidemics: Phenomenological and 'experience-near' explorations. Ethos

Jackson, M. (2011). Life within limits: Well-being in a World of Want. Durham NC. Duke University Press. https://doi.org/10.1215/9780822393696

Lupton, D. (1995). The Imperative of Health: Public Health and the Regulated Body. Londen: Sage, 1995.

Marsden, P. (1998). Memetics and Social Contagion: Two Sides of the Same Coin.

Moore, H. L. (2011). Still life: Hopes, Desires, and Satisfactions. Cambridge, UK: Polity Press

Oxford English Dictionary. Accesses via Statsbiblioteket on 04.0216: http://www.oed.com. ez.statsbiblioteket.dk:2048/

Pfeiffer, J and Nichter, M. (2008) What Can Critical Medical Anthropology Contribute to Global Health? Medical Anthropology Quarterly 22 (4): 410-415. DOI: 10.1111/j.15481387.2008.00041.x

Ratner, C. (2000). Agency and Culture. Journal for the Theory of Social Behaviour. Volume 30, Issue 4, pages 413-434, December 2000. DOI: 10.1111/1468-5914.00138 
Rosenberg, C. (1992). Explaining Epidemics and Other Studies in the History of Medicine. Cambridge: Cambridge University Press

Shaw JE, Sicree RA, Zimmet PZ (2010). Global estimates of the prevalence of diabetes for 2010 and 2030. Diabetes Res Clin Pract. 2010 Jan; 87(1):4-14. DOI: 10.1016/j.diabres.2009.10.007

Seeberg and Meinert (2015). Can epidemics be noncommunicable? Reflections on the spread of noncommunicable diseases. Medicine Anthropology Theory 2, 54-71.

Sheper-Hughes, N. (1992). Death without weeping: the violence of everyday life in Brazil. Berkeley: University of California Press, 1992

Spitzer, H. and Twikirize, Janestic M. (2012) War-affected Children in Northern Uganda: No Easy Path to Normality. In: International Social Work, Vol. 56, No. 1 (67-79). DOI: $10.1177 / 0020872812459067$

Ugandan Bureau of Statistics (2012). Demographic Health Surveillance 2012. Ministry of Health

Veblen (1899). The Theory of the Leisure Class: An Economic Study in the Evolution of Institutions. New York, Macmillan

Verma, C.L. (2012). Truths out of Place: Homecoming Intervention, and Story-Making in War-Torn Northern Uganda. In: Children's Geographies, Vol. 10, No. 4 (441-455). DOI: 10.1080/14733285.2012.726075

Vorhölter, J. (2012). Negotiating Social Change: Ugandan Discourses on Westernisation and Neo-colonialism as Forms of Social Critique. In: The Journal of Modern African Studies, Vol. 50, No. 2 (283-307). DOI: 10.1017/S0022278X12000055

Vorhölter, J. (2014). Youth at the Crossroads. Discourses on Socio-Cultural Change in PostWar Northern Uganda. PhD dissertation. Published in 2014 by Göttingen University Press as volume 7 in "Göttingen Series in Social and Cultural Anthropology"

Weber, M. [1922](1978). [1922] 1978. Economy and Society. 2 vols. Translated and edited by Guenther Roth and Claus Wittich. Berkeley: University of California Press.

Weber, M (1949). 1949. The Methodology of the Social Sciences. Edited by Edward Shils and H. Finch. New York: Free Press.

Whyte, S.R.; Babiiha, S. M.; Mukyala, R. and Meinert, L. (2012). Remaining Internally Displaced: Missing Links to Security in Northern Uganda. In: Journal of Refugee Studies, online publication (1-19). DOI: 10.1093/jrs/fes040

Whyte S.R. (2014). The Publics of New Public Health. Life Conditions and "Lifestyle Diseases" in Uganda. In Making and Unmaking Public Health in Africa by Prince R. and Marsland R. (eds). Ohio University Press 